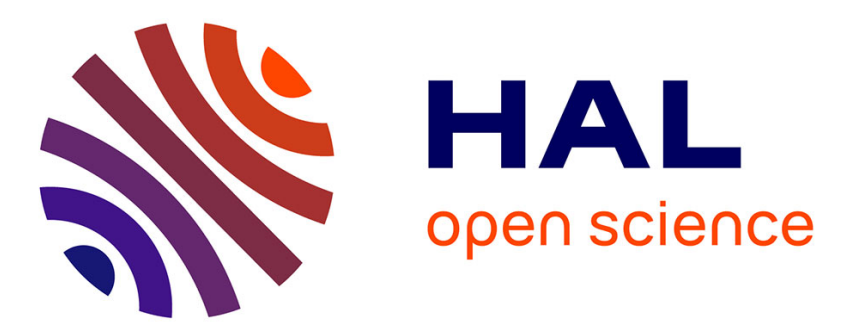

\title{
Notes sur le reboisement: Rares de mélèze et grosseur des graines
}

\author{
Pierre Bouvarel, Michel Lemoine
}

\section{To cite this version:}

Pierre Bouvarel, Michel Lemoine. Notes sur le reboisement: Rares de mélèze et grosseur des graines. Revue forestière française, 1958, 5, pp.348-350. 10.4267/2042/27409 . hal-03382176

\section{HAL Id: hal-03382176 https://hal.science/hal-03382176}

Submitted on 18 Oct 2021

HAL is a multi-disciplinary open access archive for the deposit and dissemination of scientific research documents, whether they are published or not. The documents may come from teaching and research institutions in France or abroad, or from public or private research centers.
L'archive ouverte pluridisciplinaire HAL, est destinée au dépôt et à la diffusion de documents scientifiques de niveau recherche, publiés ou non, émanant des établissements d'enseignement et de recherche français ou étrangers, des laboratoires publics ou privés. 


\section{NOTES SUR LE REBOISEMENT}

\section{RACES DE MELEZZE ET GROSSEUR DES GRAINES}

La question des races de mélèze a été évoquée récemment à plusieurs reprises dans la Revue Forestière (J. PARdé: Plaidoyer pour le mélèze, août-septembre I957 - P. Bouvarel: Appel pour la sélection de mélèzes d'élite, juillet 1957). Rappelons brièvement les principales divisions infraspécifiques de cette espèce.

I ${ }^{\circ}$ Alpes. - C'est la plus importante. Le mélèze occupe des stations allant de $300 \mathrm{~m}$ d'altitude dans le Wiener Wald en Autriche, jusqu'à la limite de la végétation forestière. Il domine dans les vallées intérieures à climat de type continental (par exemple, Briançonnais, Tyrol), mais il existe aussi sur la bordure Nord du massif, ourerte aux influences océaniques, à une altitude nettement plus basse.

$2^{\circ}$ Suclètes - Tatras. - Le mélèze forme en Tchécoslovaquie des forêts naturelles, d'une part dans les Sudètes, au Nord-Est d'Ostrava, d'autre part clans les Monts Tatras. Ces types, souvent mélangés au hêtre dans des peuplements situés de 300 à $800 \mathrm{~m}$ d'altitulc, paraissent moins exigeants en lumière que le mélèze des Alpes.

$3^{\circ}$ Polognc. - Les mélèzes polonais forment des peuplements dispersés de la Haute Silésie jusqu'à la latitude de Varsovie. C'est un type de basse altitude, adapté à un climat continental sec.

Les graines qui sont offertes actuellement aux reboiseurs français proviennent essentiellement de deux régions:

- Briançonnais: I 200 ̀े $1700 \mathrm{~m}$ (le terme "Briançonnais )" étant entendu au sens large, et comprenant également l'Embrunais et le Queyras).

- Autriche : 300 à I $200 \mathrm{~m}$.

Ces cleux provenances sont de valeur très inégale: le mélèze de Briançon, arbre de haute altitude, adapté au climat lumineux et relativement sec de la zone interne des Alpes, ne convient pas pour les reboisements en plaine et dans les régions soumises à un climat atlantique et situées à moins de I ooo m d'altitude: sa croissance est 
faible, il souffre des gelées tardives et des attaques de la Pezize du mélèze. Pour les reboisements dans ces régions, les provenances autrichiennes, surtout celles de basse altitude, doivent donc être préférées dans tous les cas. Les mélèzes des Sudètes constitueraient également une bonne provenance, si l'approvisionnement en graines était plus facile. Nous mentionnons pour mémoire les beaux reboisements anciens existant dans les plaines françaises: ils ont fait la preuve de leur adaptation aux conditions écologiques de ces régions et ils constituent une source de graines intéressante.

Il serait donc fort important pour les reboiseurs de pouvoir distinguer sur les graines elles-mêmes les deux provenances Briançon et Autriche. La grosseur des graines est un caractère héréditaire qui varie suivant les races et les écotypes d'une même espèce, mais pour la plupart des espèces, ces différences sont trop faibles et la variation à l'intérieur d'une même race trop large (autrement dit, les courbes de fréquence se recoupent largement) pour qu'on puisse utiliser avec certitude ce caractère pour reconnaitre les graines de diverses provenances.

Pour le mélèze, au contraire, et spécialement pour les provenances qui nous intéressent, la grosseur des graines permet un diagnostic sûr: le tableau ci-dessous et le graphique qui l'accompagne, ont été établis d'après les essais faits sur divers lots de graines au laboratoire d'analyse des graines de la Station de Recherches forestières de Nancy.

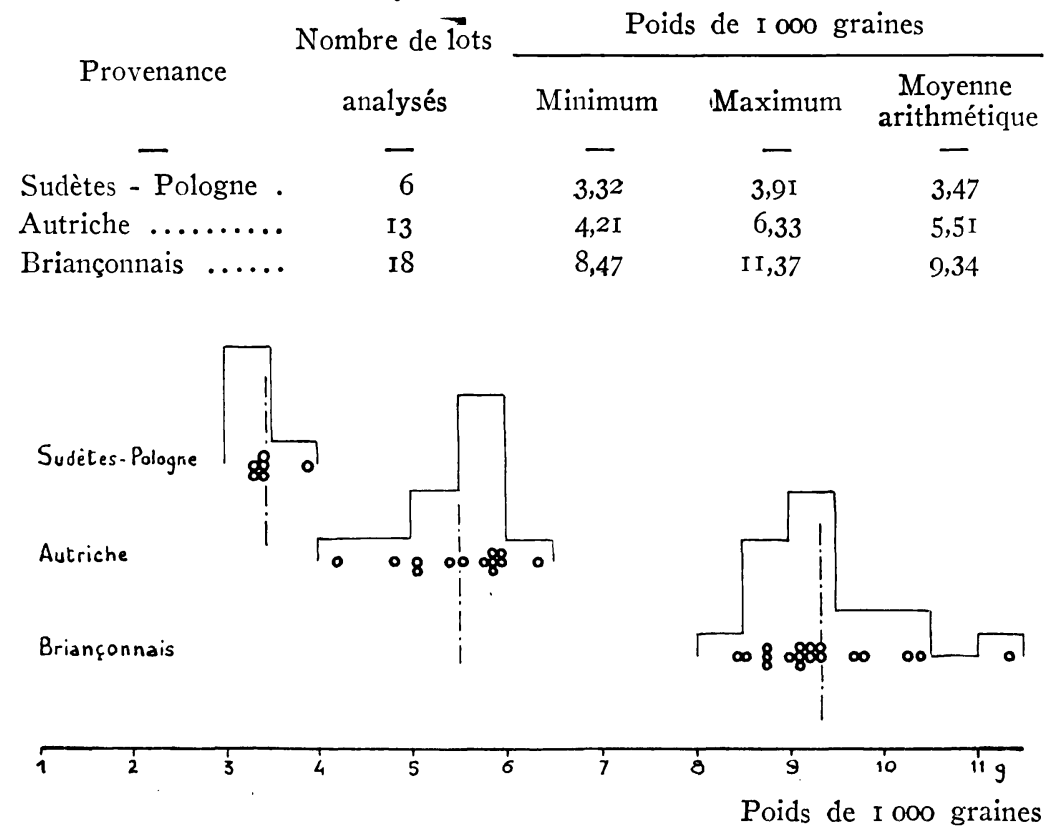


Les mélèzes du Briançonnais ont donc des graines beaucoup plus grosses que les mélèzes d'Autriche, et la distinction est sûre, puisque les plus grosses graines d'Autriche sont encore beaucoup plus petites que les plus petites de Briançon.

Les mélèzes des Sudètes et de Pologne ont des graines encore plus petites que celles d'Autriche, moins grosses même que celles du mélèze du Japon (moyenne 3,92 g). Un seul doute subsiste: nous n'avons pas analysé de lots d'Autriche provenant d'une altitude supérieure à I $200 \mathrm{~m}$; il est possible que ces graines soient


Graines de mélèze: à gauche, Briançonnais; à droite, Autriche. (Extrait de: J. Pourter. Repeuplements artificiels, $2^{\ominus}$ édition.)

plus grosses. Mais ces provenances autrichiennes de haute altitude n'ont pas plus d'intérêt pour les reboisements en plaine que les graines de Briançon. Il est donc possible d'affirmer que tout lot pour lequel le poids de I ooo graines est situé entre $4 \mathrm{~g}$ et $6,5 \mathrm{~g}$ , soit I 55000 à 250000 graines au kilogramme) provient d'une altitude relativement basse dans le Nord des Alpes et convient pour les reboisements en plaine et sous climat atlantique; tout lot pour lequel le poids de I ooo graines est compris entre 8 et I2 $\mathrm{g}$ (soit 83000 à $\mathrm{I} 25000$ graines au kilogramme) provient très probablement du Briançonnais. Les lots compris entre 3 et $4 \mathrm{~g}$ proviennent des Sudètes ou de Pologne.

$$
\text { P. Bouvarel. - M. Lemoine. }
$$

